\title{
Management der zervikalen atypischen Mykobakteriose im Kindesalter
}

van Bremen $\mathrm{T}^{1}$, Biesinger E. ${ }^{2}$, Göke F. ${ }^{3}$, Keiner S. ${ }^{1}$, Schröck A. ${ }^{1}$, Bootz F. ${ }^{1}$

${ }^{1}$ Klinik und Poliklinik für Hals-Nasen-Ohren Heilkunde/-Chirurgie; Universitätsklinikum Bonn ${ }^{2}$ HNO-Zentrum Traunstein ${ }^{3}$ Institut für Pathologie, Universitätsklinikum Bonn

\section{I)

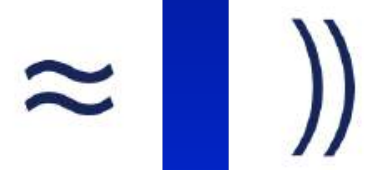

Klinik und Poliklinik für

Hals-Nasen-Ohren-Heilkunde/-Chirurgie Universitat Bonn

\section{Einleitung}

Die atypische oder auch nicht-tuberkulöse Mykobakteriose ist eine seltene Ursache einer zervikalen Lymphadenitis, welche erstmalig in den 1950er Jahren beschrieben wurde. Atypische mykobakterielle Organismen wurden bei Patienten entdeckt bei denen primär eine Tuberkulose angenommen wurde, die jedoch nicht auf die damals etablierte antituberkulöse Therapie reagierten. Seitdem gilt die komplette chirurgische Exzision als Therapie der Wahl, obwohl ein primär medikamentös-konservatives Vorgehen in der Literatur immer wieder diskutiert wird.

Seit mehr als 60 Jahren wir die Einteilung nach Runyon verwendet, der das Pigmentierungsverhalten (lichtabhängig oder lichtunabhängig) und die
Wachstumsgeschwindigkeit zugrunde liegt (Tabelle 1). Heutzutage spielen aber auch molekularbiologische und genetische Analysen eine immer größere Rolle, durch die immer wieder neue Spezies entdeckt werden. Zurzeit sind über 160 verschiedene Spezies bekannt - eine zervicofaziale Lymphadenitis wird jedoch in $70-90 \%$ von Bakterien des „M. aviumLymphadenitis wird jedoch in 70-90\% von Bakterien des „M. aviumintrazellulare- Komplex" hervorgerufen. Atypische Mykobakterien sind
umweltstabil, leben in Erdböden, Gewässern oder im Tierreich. Als Eintrittsforte dienen Haut, Mundschleimhaut, Tonsillen und das Zahnfleisch.

Die Infektion mit atypischen Mykobakterien als Ursache einer zervikalen Lymphadenitis ist mit 1,8 Fällen pro 100000 Einwohner selten.

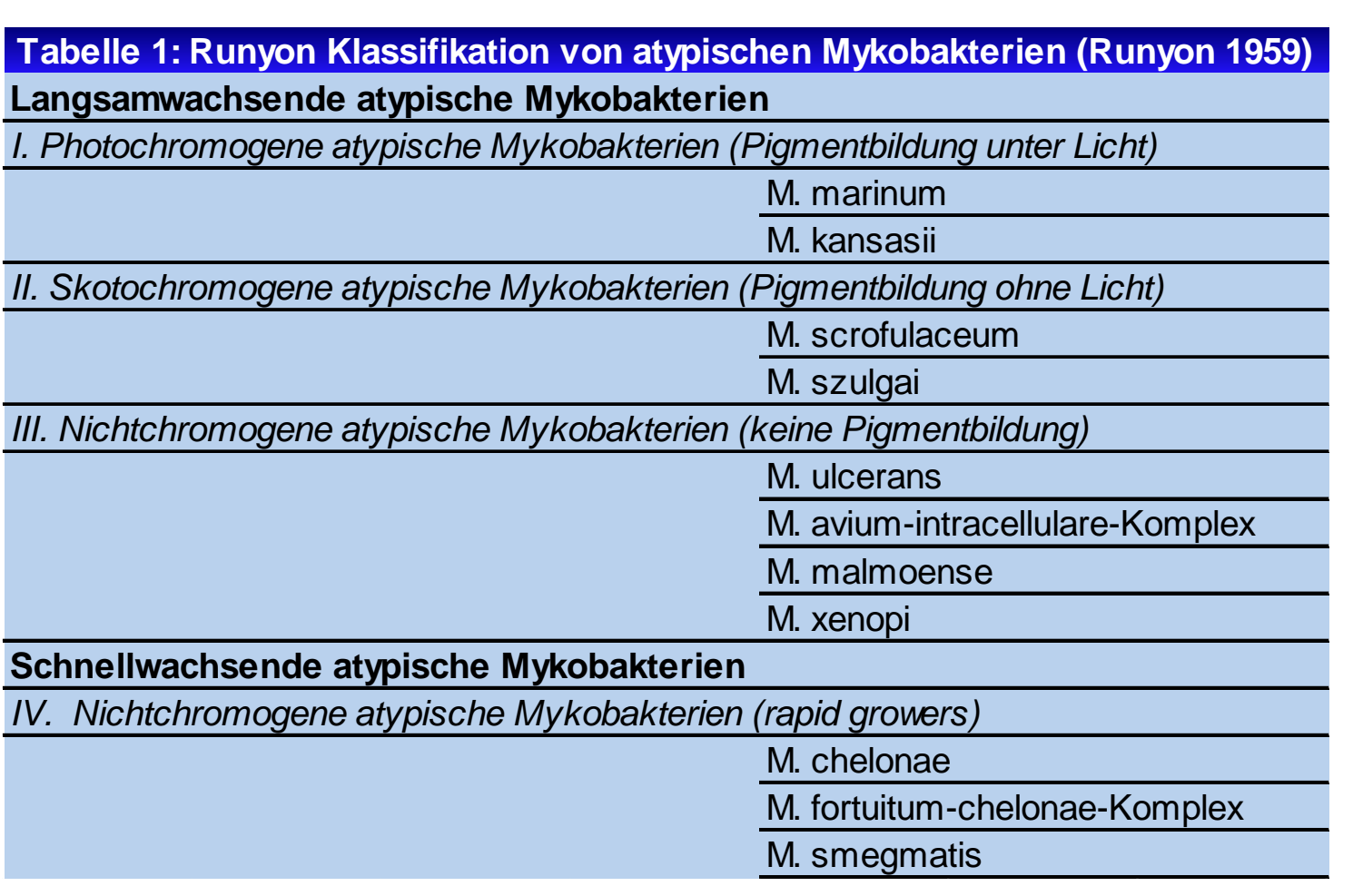

\section{Klinik und Diagnostik}

Klinik:

-das Erkrankungsalter bei immunkompeteten Kindern liegt zwischen 12 Monaten und 5 Jahren

•typisch ist eine indolente, derbe, unilaterale Lymphadenitis

-in fortgeschrittenen Stadien können Hautrötungen und Fistelbildungen auftreten

\section{Diagnostik:}

•ein spezifischer mikrobiologischer Nachweis gelingt nur in 40-60\% der Fälle und dauert in der Regel einige Wochen

-molekularbiologisch stehen die PCR und die Sondenhybridisierung mit einer Sensitivität von $96,4-100 \%$ und Spezifität von $75 \%$ zur Verfügung

- die Bildgebung gibt Hinweise zur Ausdehnung und dient zur Planung eines operativen Vorgehens (Abbildung 1)

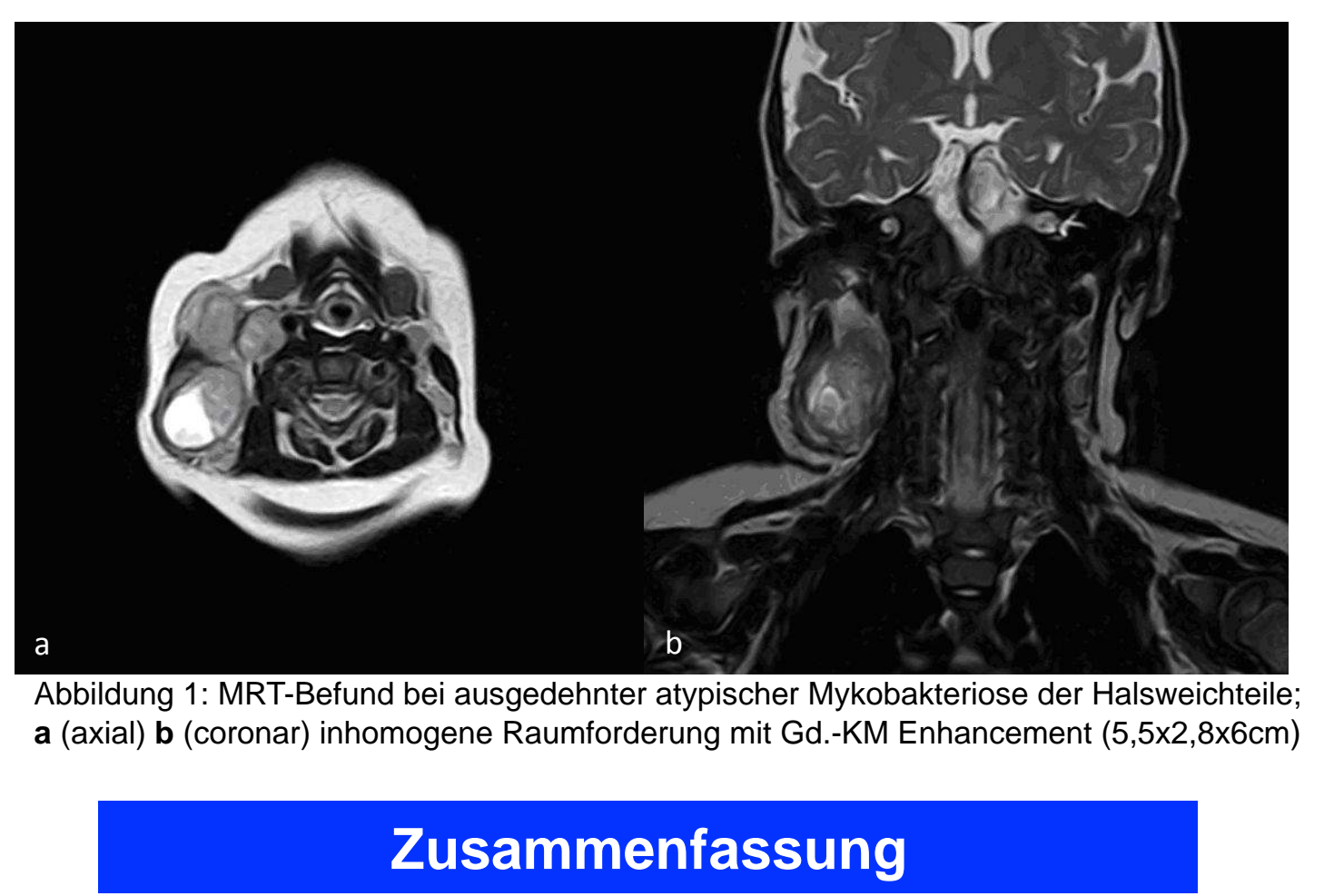

Die atypische Mykobakteriose ist eine seltene Ursache einer zervikalen Lymphadenitis im Kindesalter. Die unspezifische Klinik und Diagnostik führt häufig zu einer späten Diagnose. Hierdurch wird das therapeutische Management erschwert. Es fehlen kontrollierte-randomisierte Studien, die klar den Nutzen einer bestimmten Behandlungsform herausstellen, die komplette chirurgische Exzision ist jedoch als effektive Behandlungsform etabliert, häufig begleitet von einer antimikrobiellen Therapie. Die Inzision eines abszedierenden Lymphknotens bei einem zervikalen Befall sollte aufgrund der hohen Rate an Rezidiven verhindert werden.

\section{Therapie}

\section{Chirurgischer Ansatz:}

- Therapie der Wahl“" mit Heilungsraten $>90 \%$ [1]

- definitives Therapieverfahren mit gleichzeitiger Gewinnung von Gewebe zur Diagnostik

-eine frühe Intervention vermeidet Komplikationen

•eine Inzision führt zu häufigen Rezidiven [1]

Medikamentöser Ansatz:

schlechtere Heilungsraten gegenüber chirurgischem Vorgehen (66\% vs. $96 \%)$ [2]

-es existieren keine randomisierten Studien mit genauen Definitionen über Regime, Dauer, Dosis und Indikation

\section{Kombinierter Ansatz:}

-durch postoperative Monotherapie mit Clarithromycin weniger Rezidive [3] -Zweifachtherapie mit Clarithromycin und Rifampicin nach inkompletter Resektion

\section{Beobachtender Ansatz:}

Zeharia et al. konnten an 92 Patienten bei $71 \%$ eine Remission nach 6 Monaten und eine komplette Ausheilung nach 12 Monaten nachweisen [4] •keine Langzeitergebnisse über Rezidive oder Spätkomplikationen [5] -hohe Akzeptanz der Eltern notwendig

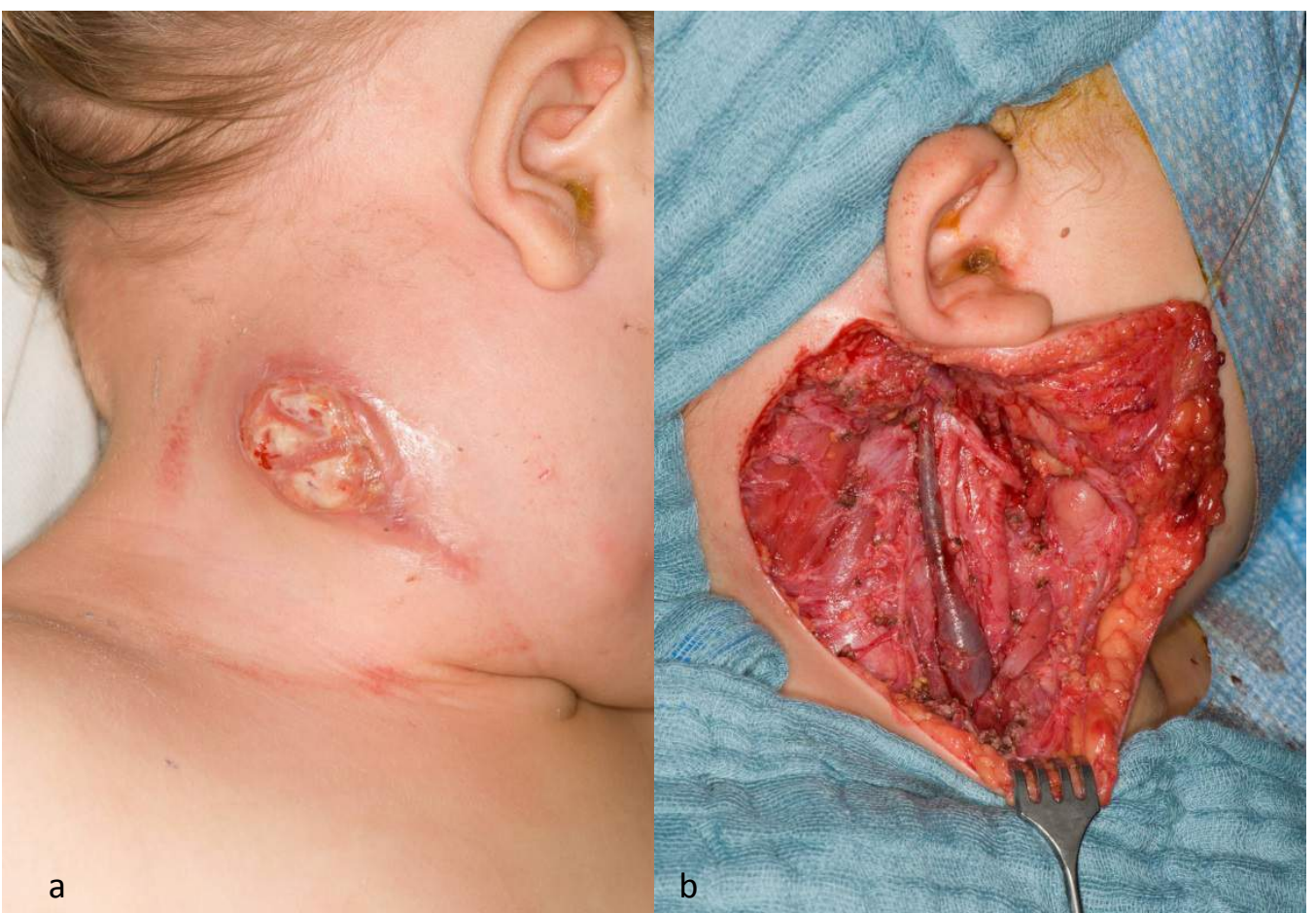

Abbildung 2 a: Typischer Befund mit perkutaner Perforation bei einem 14 Monate alten

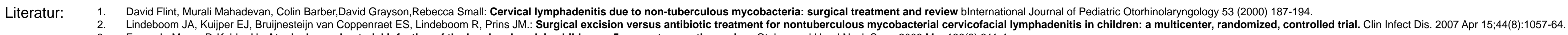
Fraser L, Moore P, Kubba, H.: Atypical mycobacterial infection of the head and neck in children: a 5-year retrospective review. Otolaryngol Head Neck Surg. 2008 Mar; $138(3): 311-4$.
Lindeboom JA.: Conservative wait-and-see therapy versus antibiotic treatment for nontuberculous mycobacterial cervicofacial lymphadenitis in children. Clin Infect Dis. 2011 Jan 15:52(2):180-4 5. Zeharia A, Eidlitiz-Markus T, Haimi-Cohen Y, Samra Z, Kaufman L, Amir J. Management of nontuberculous mycobacteria-induced cervical lymphadenitis with observation alone. Pediatr Infect Dis J. 2008 Oct:27(10):920-2.
and 